Research Paper

\title{
Altered expression of renin-angiotensin system receptors throughout colorectal adenoma-adenocarcinoma sequence
}

\author{
Maider Beitia ${ }^{1,2,5}$, Jon Danel Solano-Iturri 3,5 , Peio Errarte' 2,5 , Begoña Sanz ${ }^{2,5}$, Itxaro Perez ${ }^{1,5}$, María C.

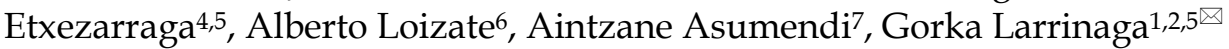 \\ 1. Department of Nursing I, School of Nursing, University of the Basque Country (UPV/EHU), Leioa, Bizkaia, Spain \\ 2. Department of Physiology, Faculty of Medicine and Dentistry, University of the Basque Country (UPV/EHU), Leioa, Bizkaia, Spain \\ 3. Department of Anatomic Pathology, Cruces University Hospital, University of the Basque Country (UPV/EHU), Barakaldo, Bizkaia, Spain \\ 4. Department of Anatomic Pathology, Basurto University Hospital, University of the Basque Country (UPV/EHU), Bilbao, Bizkaia, Spain \\ 5. BioCruces Health Research Institute, Barakaldo, Bizkaia, Spain \\ 6. Department of Surgery, Basurto University Hospital, University of the Basque Country (UPV/EHU), Bilbao, Bizkaia, Spain \\ 7. Department of Cell Biology and Histology, School of Medicine and Dentistry, University of the Basque Country (UPV/EHU), Leioa, Bizkaia, Spain
}

$\triangle$ Corresponding author: Gorka Larrinaga, Department of Nursing I, Medicine and Nursing Faculty, University of the Basque Country (UPV/EHU), PO Box 699, 48080 Bilbao, Bizkaia, Spain. Fax: +34.94.601.5662; Phone: +34.94.601.8076; e-mail: gorka.larrinaga@ehu.es

(c) Ivyspring International Publisher. This is an open access article distributed under the terms of the Creative Commons Attribution (CC BY-NC) license (https://creativecommons.org/licenses/by-nc/4.0/). See http://ivyspring.com/terms for full terms and conditions.

Received: 2018.12.27; Accepted: 2019.03.27; Published: 2019.06.02

\begin{abstract}
Background and Objective: Colorectal cancer (CRC) is a major health problem in developed countries. Adenomatous lesions in the large bowel are the main precursors of CRC and the adenoma-adenocarcinoma sequence still provides a solid model for research on carcinogenesis. The finding of local renin-angiotensin systems (RAS) has been crucial to understand the role of this peptidergic system in cancer and has opened new perspectives in the study of colorectal carcinogenetic processes.

Methods: In this study we analyzed the immunohistochemical expression of three main RAS receptors (AT1, AT2 and MAS) in a large series of CRC samples $(n=161)$, including uninvolved intestinal mucosa-adenoma-adenocarcinoma sequences from the same patients $(n=50)$.

Results: 1) AT1 and AT2 showed a biphasic expression pattern along the sequence. The expression significantly decreased in adenomas with respect to uninvolved mucosa but increased in CRCs. 2) AT2 expression was lower in advanced CRCs with high local invasion (pT4), high stage (IV), high nodal (N2) and vascular invasion. 3) MAS receptor was moderately expressed in the uninvolved mucosa and in adenomas. This expression increased very significantly in CRC tissues.

Conclusions: These results suggest that: 1) RAS receptors are differentially regulated as the genetic and epigenetic alterations accumulate throughout the uninvolved mucosa-adenoma-CRC sequence. 2) Loss of AT2 expression could contribute to the aggressive behavior of advanced CRC cells.
\end{abstract}

Key words: Renin-angiotensin system, receptor, adenoma, colorectal cancer, biomarkers

\section{Introduction}

Colorectal cancer (CRC) is one of the commonest malignancies worldwide (1) and the first in Spain in terms of incidence (2). Huge resources have been invested in prevention and early diagnosis of this disease. Population-based screening campaigns try to discover tumors and precursor lesions as early as possible, aiming to decrease the incidence of the disease, to simplify the clinical management of patients once the lesion develops, and to improve survival (3). However, despite the advances in early screening programs, surgery and radio and chemotherapy, it is still the second leading cause of cancer deaths (1).

From a pathological perspective, adenomatous lesions in the large bowel are fully accepted precursors of $\mathrm{CRC}$ and the adenoma-adenocarcinoma 
sequence still provides a solid model for research on carcinogenesis $(4,5)$. However, a large number of still largely unknown cellular metabolic processes are involved in the origin and development of these neoplastic processes, which need to be elucidated $(4,6)$.

The renin-angiotensin system (RAS) was traditionally described as an endocrine pathway that regulates cardiovascular function and hydro-electrolytic balance (7). However, the newly expanded view of RAS describes local functions (paracrine, autocrine, and intracrine) and demonstrates that this peptidergic system regulates long-term biologic processes such as cell growth and proliferation $(7,8)$ (see Figure 1). Imbalance in components of RAS has been associated with cancer development and progression and, therefore, receptors and enzymes of RAS have been proposed as potential diagnostic/prognostic biomarkers and therapy targets of this disease (7-13).

Since Lever et al (1998) described for the first time that angiotensin-converting enzyme inhibitors (ACEi) may protect against cancer, epidemiologic studies describing this protective role of RAS inhibitors have increased exponentially (14-16). Thus, it has been observed that the long-term use of angiotensin II type- 1 receptor (AT1) blockers (ARBs) and ACEi is associated with a decreased incidence of CRC (17) and with a lower risk of recurrence and mortality in CRC patients (15). Moreover, it has been reported that the use of ARBs enhance the response to vascular endothelial growth factor (VEGF)- targeted therapies such as bevacizumab in metastatic CRC patients (18) and proposed the use of ARBs for personalized therapies in KRAS mutant CRC patients (19). However, the use of antihypertensive drugs for cancer treatment needs to be fully studied as some studies have reported controversial results, reporting pleiotropic effects of RAS in different types of cancers $(20,21)$.

Studies in CRC cell lines and in rodents have demonstrated that RAS blockade reverses Angiotensin II (Ang II) induced angiogenesis, proliferation, epithelial to mesenchymal transition (EMT) and migration of CRC cells $(9,11,22-24)$. On the other hand, studies performed in human CRC tissues described higher ACE activity in tumors with respect to the uninvolved intestinal mucosa (25). We also observed that lower activity of aspartyl-aminopeptidase (a cytosolic angiotensinase which converts Ang II into Ang III) in CRC tissues is associated with worse 5-year survival of CRC patients (26). Studies describing differences in RAS receptors between CRC tissues and uninvolved surrounding mucosa have also been reported $(25,27)$. However, these studies were limited to few cases and did not analyze colorectal preneoplastic lesions.

Angiotensinogen

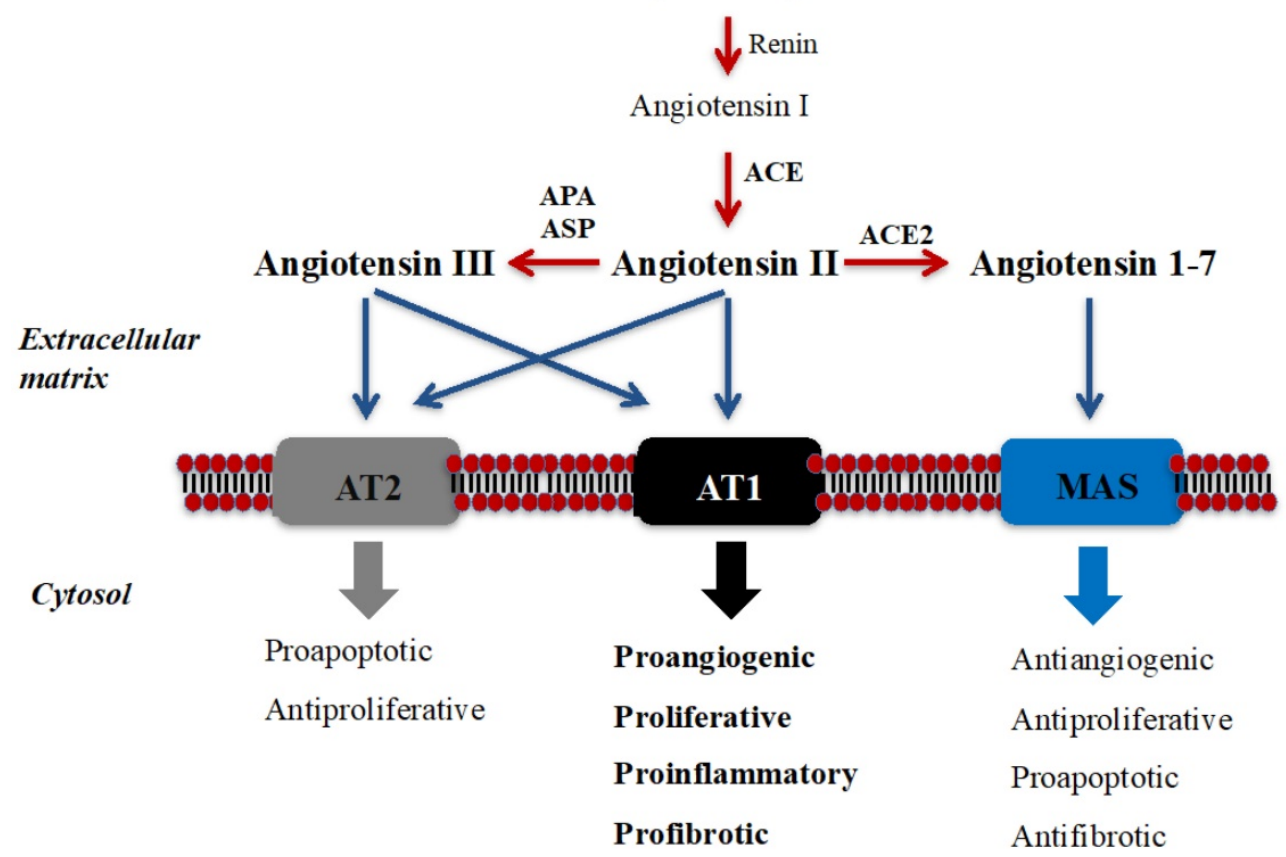

Fig 1. Schematic illustration of RAS and its local long-term biologic functions. Angiotensin II (Ang II), the best-known bioactive peptide of RAS, is mainly generated by the catalytic action of angiotensin-converting enzyme (ACE), and binds to Angiotensin II Type 1 (AT1) and Type 2 (AT2) receptors [7-10]. Ang II is metabolized to angiotensin III (Ang III) by "angiotensinases" (aminopeptidase A/APA and aspartil-aminopeptidase/ASP), and Ang III also binds to these receptors. Angiotensin 1-7 (Ang 1-7) is mainly produced from Ang II by ACE2 and binds to MAS receptor. Ang II binding to AT1 activates long-term local effects (represented in bold) in several tissues. These biological effects could be counterbalanced by the action of Ang II/Anglll/AT2 axis and by the Ang 1-7/MAS axis [7-10]. Peptide transformation is symbolized in red arrows, while black arrows show each bioactive peptide binding to their receptors. 
With the objective to throw more light to the study of RAS receptors in CRC tissues, we analyzed the immunohistochemical expression of AT1, AT2 and MAS receptors in a series of CRC samples, including uninvolved mucosa-adenoma-adenocarcinoma sequences from the same patients, and stratified the obtained results with standard histopathological parameters for tumor prognosis and survival.

\section{Materials \& Methods}

The authors declare that all the experiments carried out in this study comply with the current Spanish and European Union legal regulations. Samples and data from patients included in this study were provided by the Basque Biobank for Research-OEHUN (www.biobancovasco.org). All patients were informed about the potential use for research of their surgically resected tissues, and accepted this eventuality by signing a specific document approved by the Ethical and Scientific Committees of the Basque Country Public Health System (Osakidetza) (CEIC 11/51).

Table 1. Clinical and pathological data from CRC patients $(n=161)$

\begin{tabular}{|c|c|c|}
\hline & & Average (\%) \\
\hline Age average (range) & & $70(34-93)$ \\
\hline \multirow[t]{2}{*}{ Gender } & Male & $113(70 \%)$ \\
\hline & Female & $48(30 \%)$ \\
\hline \multirow[t]{2}{*}{ Histologic subtype } & Intestinal-type adenocarcioma (AdC) & $145(90 \%)$ \\
\hline & Mucinous carcinoma $(\mathrm{MuC})$ & $16(10 \%)$ \\
\hline \multirow[t]{3}{*}{ Histologic grade (G) } & G1 & $6(4 \%)$ \\
\hline & G2 & $136(84 \%)$ \\
\hline & G3 & $19(12 \%)$ \\
\hline \multirow[t]{3}{*}{ Local invasion (pT) } & pT2 & $42(26 \%)$ \\
\hline & pT3 & $105(65 \%)$ \\
\hline & pT4 & $14(9 \%)$ \\
\hline \multirow[t]{3}{*}{ Affected lymph nodes (N) } & No & $95(59 \%)$ \\
\hline & N1 & $51(32 \%)$ \\
\hline & N2 & $15(9 \%)$ \\
\hline \multirow[t]{4}{*}{ Stage (TNM system) } & I & $34(21 \%)$ \\
\hline & II & $60(37 \%)$ \\
\hline & III & $63(39 \%)$ \\
\hline & IV & $4(3 \%)$ \\
\hline \multirow[t]{2}{*}{ Vascular Invasion } & No & $141(88 \%)$ \\
\hline & Yes & $20(12 \%)$ \\
\hline \multirow[t]{2}{*}{ Lymphatic Invasion } & No & $133(83 \%)$ \\
\hline & Yes & $28(17 \%)$ \\
\hline \multirow[t]{2}{*}{ Perineural invasion } & No & $139(86 \%)$ \\
\hline & Yes & $22(14 \%)$ \\
\hline
\end{tabular}

\section{Patients}

161 patients diagnosed with CRC were prospectively and consecutively included in the study. Males predominated in the series $(113 \mathrm{M} / 48 \mathrm{~F})$, being the average age 69.7 years for males and 70.9 years for females. All patients received partial colectomies. In 50 of these patients, both adenomatous polyps and adenocarcinomas were diagnosed. These cases were used to analyze immunohistochemical expression of RAS receptors throughout the uninvolved mucosa-adenoma-adenocarcinoma sequence.

Follow-up was closed by November 30, 2018. Mean follow-up was 50 months (range 3-83 months). At that time, 45 patients had died of disease. AJCC system (8 $8^{\text {th }}$ Edition) (28) has been applied to assign Stage and Grade to each case. Clinical and pathological data included in the study were retrieved from the patients' clinical records and are summarized in Table 1.

Gender, age and tumor aggressiveness of this series was similar to that described by cancer registries of our province (Biscay) (29).

\section{Immunohistochemistry}

Formalin-fixed and paraffin-embedded tissue from CRCs, adenomatous polyps and the uninvolved surrounding mucosa were immunostained with a monoclonal antibody specific for AT1 (Ab9391, Abcam), a polyclonal antibody specific for AT2 (Ab19134, Abcam) and a polyclonal antibody specific for MAS (AAR-013, Alomone labs) at 1/65, 1/100 and $1 / 50$ dilutions, respectively. The immunostaining process was performed following routine methods in an automatic immunostainer (Dako Autostainer Plus, Dako-Agilent). Briefly, antigen retrieval was carried out in low pH buffer (K8005, Dako) for 20 mins at $95^{\circ} \mathrm{C}$ for AT1 and in citrate buffer $(10 \mathrm{mM}, \mathrm{pH}=6)$ for 15 minutes at $100^{\circ} \mathrm{C}$ for AT2 and MAS. The samples were incubated with the corresponding primary antibody for 1 hour at room temperature. Then, the primary antibody was washed and samples were incubated for 20 minutes with secondary anti-mouse antibody (K8021, Dako) for AT1, with secondary anti-rabbit antibody (K8009, Dako) for AT2 and without secondary antibody for MAS. EnVision-Flex detection system together with a HRP enzyme labeled polymer (SM802, Dako) was employed. A positive reaction was visualized with diaminobenzydine (DAB) solution (DM827, Dako) followed by counterstaining with haematoxylin (K8008, Dako).

For AT1 and AT2 evaluation, slides were reviewed under light microscopy. Stromal cells and blood vessels in lamina propia served as strong positive internal control. In both cases, based on the decreasing strong granular cytoplasmic staining observed in apical non-neoplastic epithelial cells and although intensity but no signaling pattern differences were observed comparing with previous works (30), a three level scoring was done according to negative, weak and strong staining.

To define MAS receptor's positive staining a kidney core sampling was used as external control, where epithelial cells from renal tubules were positive 
(31). A three level semiquantitative scale system was also proposed (negative, weak and strong).

The specimens were independently evaluated by two observers and discordant cases were jointly reviewed followed by a conclusive judgment.

\section{Statistical analysis}

SPSS $₫ 23.0$ software was used for the statistical analysis. Chi-square $\left(\chi^{2}\right)$ test was used to analyze the association between categorical AT1, AT2 and MAS expression and pathological variables of CRCs, and to detect differences throughout the adenoma-adenocarcinoma sequence. Spearman rho test was used to correlate the expression of these receptors with patients' age and sex. Kaplan-Meier curves and log-rank test were performed to evaluate overall survival of the series according to the status of AT1, AT2 and MAS expression in CRC. Multivariate analysis (Cox regression model) was used to test the independent effects of clinical and pathological variables on survival.

\section{Results}

\section{Immunohistochemical expression of AT1, AT2 and MAS receptors in colorectal tissues from CRC patients.}

Figure 2 shows the immunohistochemical expression of RAS receptors in colonic adenocarcinoma, adenoma and uninvolved adjacent mucosa.

Immunohistochemical staining for AT1 receptor reveals strong granular cytoplasmic expression in the surface of the epithelium of the uninvolved mucosa and it decreases as it approaches basal cells. It is also expressed in many cells and blood vessels in lamina propria, which serves as internal control (Fig 2D). Adenomatous polyps showed low AT1 staining (Fig 2E) whereas CRCs (Fig 2F) described strong granular cytoplasmic expression in confluent atypical glands.

AT2 expressed strong granular cytoplasmic staining in the surface of epithelial glands of the normal colonic mucosa (Fig 2G). The weak expression in adenomas (Fig 2H) contrasts with the strong cytoplasmic staining in colorectal adenocarcinomatous tissues (Fig 2I).

Weak MAS receptor staining was observed in uninvolved mucosa (Fig 2J) and adenomatous polyps (Fig 2K). Mucous filled vacuoles emphasize cytoplasmic granular pattern in basal pole of enterocytes. However, CRCs showed strong cytoplasmic staining (Fig 2L).

Differences throughout the uninvolved intestinal mucosa-adenoma-CRC sequence were very significant for all receptors $\left(\chi^{2}\right.$ test $p<0.001$ for AT1 and MAS, and $\chi^{2}$ test $p<0.01$ for AT2) (Fig 3). AT1 and AT2 receptors showed a biphasic expression pattern. The strongest staining was observed in the uninvolved adjacent mucosa, this expression decreased significantly in adenomatous polyp but then increased again in CRC. On the other hand, MAS receptor expression was weak in normal mucosa and adenomas and strongly increased in CRCs.
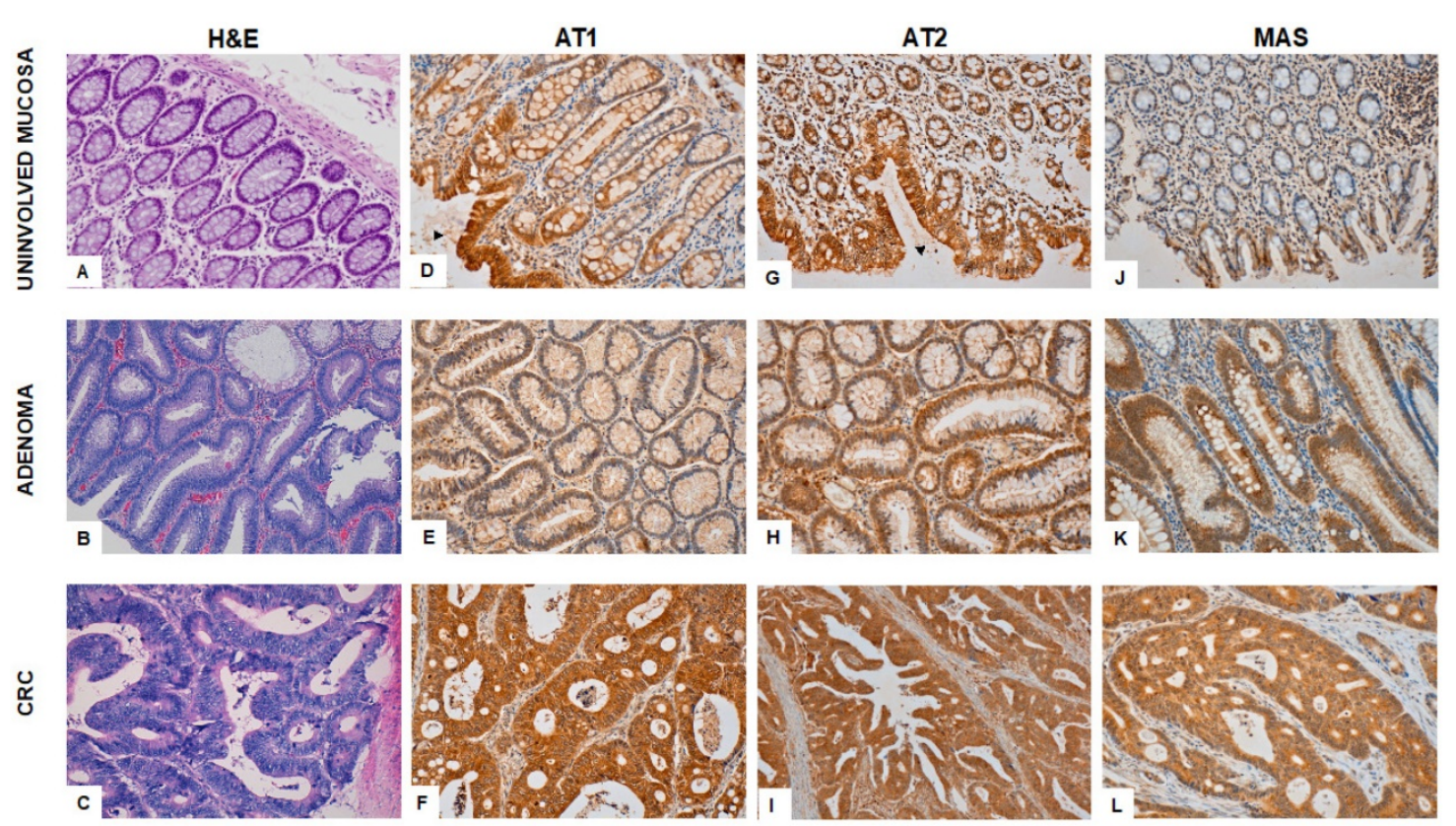

Figure 2. Immunohistochemical expression of AT1, AT2 and MAS in the uninvolved colorectal mucosa, adenomatous polyps and in carcinomas from the same CRC patients. H\&E normal colonic mucosa (A); tubular adenoma (B); Adenocarcinoma (C). Both, AT1 and AT2 expression in uninvolved mucosa (D; G) is strong in apical surface epithelium (arrowheads) and becomes weak near basal crypt glands. Weak cytoplasmic staining is seen in adenomatous mucosa (E; $H$ ) in contrast to strong expression in carcinomatous cells (F; I). MAS receptor expression sharply switches from weak staining in uninvolved $(\mathrm{J})$ and adenomatous mucosa (K) to strong cytoplasmic staining in colonic adenocarcinoma (L). 

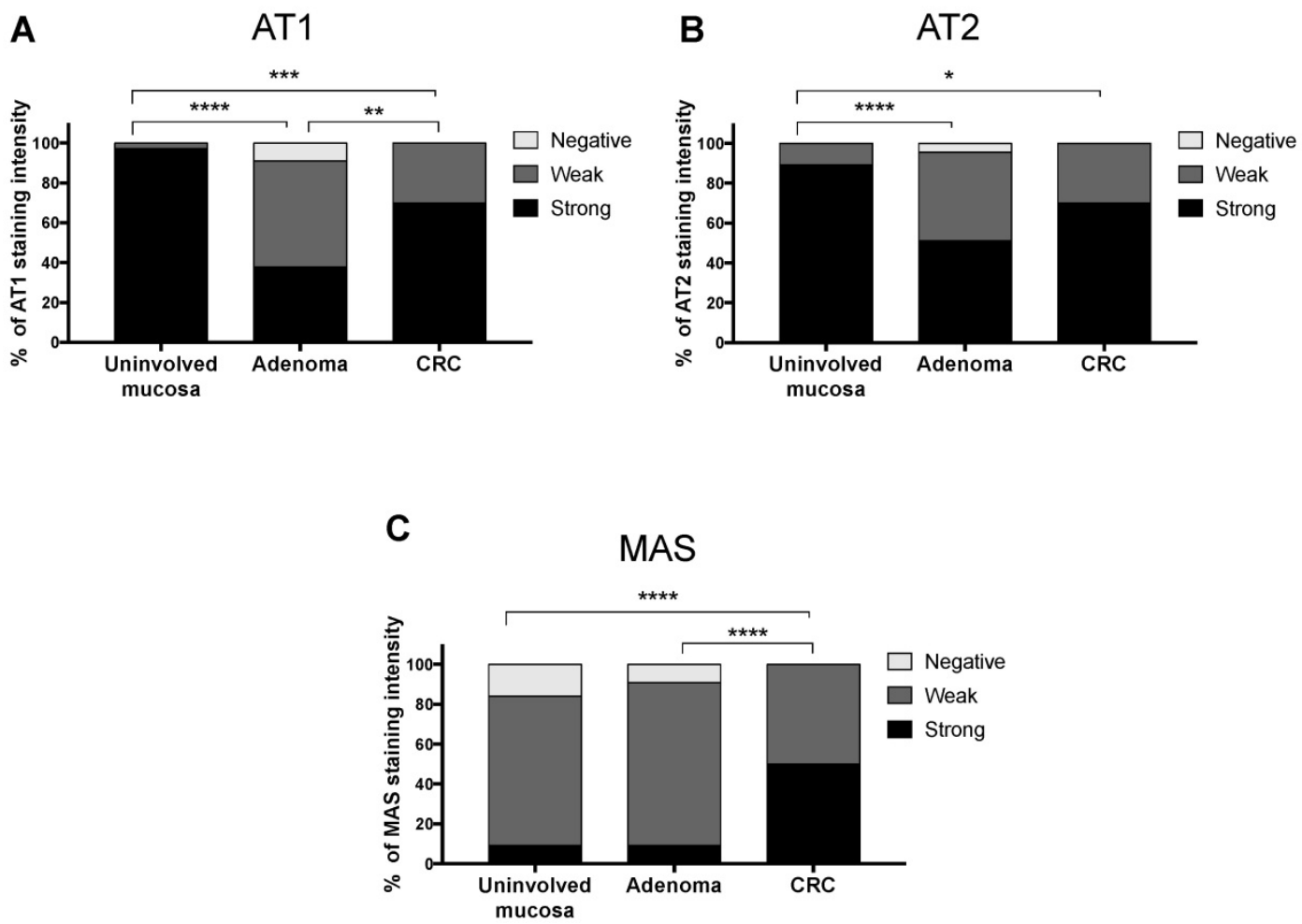

Figure 3. Differences in the immunohistochemical expression of RAS receptors throughout the uninvolved mucosa-adenoma-adenocarcinoma sequence.

Immunohistochemical expression of AT1, AT2 and MAS receptors in CRC according to clinical and pathological variables

Table 2A, B and C summarize AT1, AT2 and MAS receptor expressions in CRC tissues $(n=161)$ according to pathological variables.

First, we analyzed if there was any correlation between the immunohistochemical expression of RAS receptors in CRCs and patients' age and gender. There was not any significant correlation in any case (Spearman Rho test $p>0.05$ ).

Expression of AT1, AT2 and MAS receptors was also compared between intestinal type adenocarcinomas (AdC) and mucinous type CRCs $(\mathrm{MuC})$ and there was not any significant difference $\left(X^{2}\right.$ test $p>0.05$ ). Therefore, the rest of the analyses were performed without taking into account histologic subtype of CRCs.

AT2 receptor expression showed differences in CRC tissues depending on its local $(\mathrm{pT})$, nodal $(\mathrm{N})$ and vascular invasion (V) (Table 2A, B, C). Immunohistochemical staining of AT2 receptor was significantly lower in CRCs with high local invasion (pT4) than in pT2 ( $\chi^{2}$ test $\left.\mathrm{p}=0.002\right)$ and $\mathrm{pT} 3$ tumors $\left(\chi^{2}\right.$ test $p=0.001)$. Similarly, CRCs with four or more affected lymph nodes (N2) had lower AT2 expression than tumors without nodal invasion $(\mathrm{N} 0)$ ( $\mathrm{X}^{2}$ test $\mathrm{p}=0.03)$. Moreover, tumors with vascular invasion also showed lower AT2 expression than CRCs without it $\left(\chi^{2}\right.$ test $\left.\mathrm{p}=0.035\right)$.

Table 2A. AT1 receptor expression in CRC tissues $(n=161)$ according to pathological variables

\begin{tabular}{|c|c|c|c|c|}
\hline Variables & Weak $(\%)$ & Strong $(\%)$ & Total (n) & P value \\
\hline \multicolumn{5}{|c|}{ Histologic Subtype } \\
\hline AdC & 31.7 & 68.6 & 145 & 0.58 \\
\hline $\mathrm{MuC}$ & 25 & 75 & 16 & \\
\hline \multicolumn{5}{|c|}{ Histologic Grade } \\
\hline G1 & 16.7 & 83.3 & 6 & 0.74 \\
\hline G2 & 31.6 & 68.4 & 136 & \\
\hline G3 & 31.6 & 68.4 & 19 & \\
\hline \multicolumn{5}{|c|}{ Local Invasion (pT) } \\
\hline pT2 & 38.1 & 61.9 & 42 & 0.43 \\
\hline pT3 & 27.6 & 72.4 & 105 & \\
\hline pT4 & 35.7 & 64.3 & 14 & \\
\hline \multicolumn{5}{|c|}{ Affected Lymph Nodes (N) } \\
\hline No & 32.6 & 67.4 & 95 & 0.8 \\
\hline N1 & 27.5 & 72.5 & 51 & \\
\hline N2 & 33.3 & 66.7 & 15 & \\
\hline \multicolumn{5}{|c|}{ Stage (TNM system) } \\
\hline I & 32.4 & 67.6 & 34 & 0.94 \\
\hline II & 33.3 & 66.7 & 60 & \\
\hline III & 28.6 & 71.4 & 63 & \\
\hline IV & 25 & 75 & 4 & \\
\hline \multicolumn{5}{|c|}{ Vascular Invasion (V) } \\
\hline No & 31.2 & 68.8 & 141 & 0.91 \\
\hline Yes & 30 & 70 & 20 & \\
\hline \multicolumn{5}{|c|}{ Lymphatic Invasion (L) } \\
\hline No & 31.6 & 68.4 & 133 & 0.75 \\
\hline Yes & 28.6 & 71.4 & 28 & \\
\hline \multicolumn{5}{|c|}{ Perineural Invasion (Pn) } \\
\hline No & 30.9 & 69.1 & 139 & 0.93 \\
\hline Yes & 31.8 & 68.2 & 22 & \\
\hline
\end{tabular}


Table 2B. AT2 receptor expression in CRC tissues $(n=161)$ according to pathological variables

\begin{tabular}{|c|c|c|c|c|}
\hline Variables & Weak (\%) & Strong $(\%)$ & Total (n) & P value \\
\hline \multicolumn{5}{|c|}{ Histologic Subtype } \\
\hline AdC & 28.3 & 71.7 & 145 & \multirow[t]{2}{*}{0.2} \\
\hline $\mathrm{MuC}$ & 43.8 & 56.2 & 16 & \\
\hline \multicolumn{5}{|c|}{ Histologic Grade } \\
\hline G1 & 50 & 50 & 6 & \multirow[t]{3}{*}{0.1} \\
\hline G2 & 26.5 & 73.5 & 136 & \\
\hline G3 & 47.4 & 52.6 & 19 & \\
\hline \multicolumn{5}{|c|}{ Local Invasion (pT) } \\
\hline pT2 & 26.2 & 73.8 & 42 & \multirow[t]{3}{*}{$0.002^{(\mathrm{a})}$} \\
\hline pT3 & 25.7 & 74.3 & 105 & \\
\hline pT4 & 71.4 & 28.6 & 14 & \\
\hline \multicolumn{5}{|c|}{ Affected Lymph Nodes (N) } \\
\hline No & 26.3 & 73.7 & 95 & \multirow[t]{3}{*}{$0.1^{(\mathrm{b})}$} \\
\hline N1 & 29.4 & 70.6 & 51 & \\
\hline N2 & 53.3 & 46.7 & 15 & \\
\hline \multicolumn{5}{|c|}{ Stage (TNM system) } \\
\hline I & 26.5 & 73.5 & 34 & \multirow[t]{4}{*}{$0.16(c)$} \\
\hline II & 25 & 75 & 60 & \\
\hline III & 33.3 & 66.7 & 63 & \\
\hline IV & 75 & 25 & 4 & \\
\hline \multicolumn{5}{|c|}{ Vascular Invasion (V) } \\
\hline No & 27 & 73 & 141 & \multirow[t]{2}{*}{0.035} \\
\hline Yes & 50 & 50 & 20 & \\
\hline \multicolumn{5}{|c|}{ Lymphatic Invasion (L) } \\
\hline No & 27.1 & 72.9 & 133 & \multirow[t]{2}{*}{0.097} \\
\hline Yes & 42.9 & 57.1 & 28 & \\
\hline \multicolumn{5}{|c|}{ Perineural Invasion (Pn) } \\
\hline No & 28.1 & 71.9 & 139 & \multirow[t]{2}{*}{0.22} \\
\hline Yes & 40.9 & 59.1 & 22 & \\
\hline \multicolumn{5}{|c|}{$\begin{array}{l}\text { (a) AT2 expression was higher in } \mathrm{pT} 2(\mathrm{p}=0.002) \text { and } \mathrm{pT} 3(\mathrm{p}=0.001) \text { than in } \mathrm{pT} 4 \\
\text { CRCs. } \\
\text { (b) Differences were found between N0 and N2 CRCs }(\mathrm{p}=0.03) \text {. } \\
\text { (c) Stage IV CRCs showed lower AT1 staining than Stage I }(\mathrm{p}=0.04) \text { and II }(\mathrm{p}=0.03) \\
\text { ones. }\end{array}$} \\
\hline
\end{tabular}

Table 2C. MAS receptor expression in CRC tissues $(n=161)$ according to pathological variables

\begin{tabular}{|c|c|c|c|c|}
\hline Variables & Weak (\%) & Strong $(\%)$ & Total (n) & P value \\
\hline \multicolumn{5}{|c|}{ Histologic Subtype } \\
\hline AdC & 72.4 & 27.6 & 145 & 0.19 \\
\hline $\mathrm{MuC}$ & 87.5 & 12.5 & 16 & \\
\hline \multicolumn{5}{|c|}{ Histologic Grade } \\
\hline G1 & 100 & 0 & 6 & 0.07 \\
\hline G2 & 70.6 & 29.4 & 136 & \\
\hline G3 & 89.5 & 10.5 & 19 & \\
\hline \multicolumn{5}{|c|}{ Local Invasion (pT) } \\
\hline pT2 & 76.2 & 23.8 & 42 & 0.48 \\
\hline pT3 & 71.4 & 28.6 & 105 & \\
\hline pT4 & 85.7 & 14.3 & 14 & \\
\hline \multicolumn{5}{|c|}{ Affected Lymph Nodes (N) } \\
\hline N0 & 77.9 & 22.1 & 95 & 0.38 \\
\hline N1 & 68.6 & 31.4 & 51 & \\
\hline N2 & 66.7 & 33.3 & 15 & \\
\hline \multicolumn{5}{|c|}{ Stage (TNM system) } \\
\hline I & 70.6 & 29.4 & 34 & 0.37 \\
\hline II & 81.7 & 18.3 & 60 & \\
\hline III & 68.3 & 31.7 & 63 & \\
\hline IV & 75 & 25 & 4 & \\
\hline \multicolumn{5}{|c|}{ Vascular Invasion (V) } \\
\hline No & 74.5 & 25.5 & 141 & 0.67 \\
\hline Yes & 70 & 30 & 20 & \\
\hline \multicolumn{5}{|c|}{ Lymphatic Invasion (L) } \\
\hline No & 74.4 & 25.6 & 133 & 0.74 \\
\hline Yes & 71.4 & 28.6 & 28 & \\
\hline \multicolumn{5}{|c|}{ Perineural Invasion (Pn) } \\
\hline No & 71.9 & 28.1 & 139 & 0.15 \\
\hline Yes & 86.4 & 13.6 & 22 & \\
\hline
\end{tabular}

We did not found any significant difference of AT1 and MAS immunohistochemical expression in CRCs according to pathological variables.

\section{Immunohistochemical expression of RAS receptors according to overall survival of CRC patients.}

Kaplan-Meier curves and log-rank test did not show differences in the overall survival of patients with CRC when it was stratified by AT1 (Log-Rank test $\mathrm{p}=0.6)$, AT2 (Log-Rank test $\mathrm{p}=0.38)$ and MAS expression (Log-Rank test $\mathrm{p}=0.7)$.

\section{Discussion}

Colorectal carcinogenesis is a multistep process, which involves gradual accumulation of genetic and epigenetic alterations that result in gradual phenotypic changes throughout the colonic normal mucosa-adenoma-adenocarcinoma sequence (4-6). There have been identified key regulatory oncogenes and tumor suppressor genes whose mutations drive the transformation of this multistep model (4-6). In addition, it has allowed the identification of some proteomic profiles and signaling pathways that change along this sequence and that have been useful for the search of new CRC therapies $(4,32)$. However, a large number of proteomic changes still need to be elucidated for a better understanding of the behavior of CRC and to find useful new diagnosis/prognosis biomarkers and therapeutic targets for this disease (32).

One of the greatest hallmarks to understand the long-term functions of RAS was the discovery of a wide variety of tissues and organs that express all components of this peptidergic system (33). As previously reported $(25,27,30)$, in this study we observed strong expression of AT1 and AT2 receptors, and weak MAS expression in the epithelium of large bowel. Expression of RAS enzymes in colonic tissues has also been described $(25,26,34)$, which suggests local production of angiotensins that binds to RAS receptors and, therefore, supports the idea of the existence of local RAS in the large intestine $(9,33)$. The finding of these local RASs has been crucial to understand the role of this peptidergic system in cancer $(8,10,11)$ and has opened new perspectives in the study of colorectal carcinogenetic processes (9).

ACE/AngII/AT1 axis is the main effector of RAS at both systemic and local levels. Evidences demonstrate that imbalances in RAS that favor this axis play a critical role in VEGF-dependent angiogenesis and tumor progression, which could explain the remarkable retrospective studies that show a protective role of RAS inhibitors in CRC (9-11). Even if there is still controversy of the role of 
RAS in cancer (35), there are plenty of studies that report that patients taking antihypertensive treatments based on ARBs and ACEi show lower CRC incidence (17), recurrence and mortality (15). Moreover, the use of ARBs is associated with better overall and progression-free survival of metastatic CRC patients with VEGF-targeted therapies (bevacizumab) (18).

Studies in tumor tissues have also shown imbalances in this RAS axis. It was described that CRCs have high ACE activity (25). We also demonstrated that lower angiotensinase activity was associated with worse survival of CRC patients (26). The present work shows that AT1 was strongly expressed in the main CRCs analyzed (70\%). These evidences suggest an accumulation of Ang II in tumor microenvironment, which could activate AT1 signaling in CRC. The activation of this receptor induced the promotion of processes such as angiogenesis, proliferation, epithelial to mesenchymal transition (EMT) and migration in CRC xenograft models and in CRC cell lines, which were inhibited by ACEi and ARBs $(9,11,22-24)$.

The use of RAS inhibitors has been also associated with lower risk of colorectal adenomas, which suggests the involvement of ACE/AngII/AT1 axis in the first stages of colorectal tumorigenesis (36). In this study, we included a series of fifty premalignant and malignant lesions form the same CRC patients. AT1 was also expressed in adenomatous polyps; however, it was significantly lower than in the uninvolved mucosa and CRC. Interestingly, similar expression pattern was observed for ACE when colorectal adenomas and CRCs were compared (37). These data suggest that AT1 signaling is differentially regulated as the genetic and epigenetic alterations accumulate throughout the sequence.

The inactivation of the tumor-suppressor gene $A P C$, which leads to the activation of $\mathrm{WNT} / \beta$-catenin signaling, is an initiating event of colorectal carcinogenesis (4), and this pathway has been associated with the expression of RAS genes in other proliferative disorders (38,39). Besides, KRAS mutation is one of the key events in the colorectal adenoma-carcinoma transition and ARBs have been proposed as potential therapeutic agents for these mutant variants (19). Further studies are necessary to clarify the association between RAS and the inactivation/activation of these or other genes and epigenetic events related with this multistep carcinogenetic process.

The signaling of AT2 receptor has been associated with apoptosis and inhibition of cell proliferation (see Fig 1) $(8,11)$. The delicate balance between proliferative (via AT1) and apoptotic (via AT2) signals plays an essential role in local RASs long-term functions and in the pathophysiology of several proliferative diseases. Indeed, it has been suggested that the protective antiproliferative role of AT1 receptor blockers (ARBs) could be due, at least in part, to the effect of Ang II in AT2 receptors $(8,10,11)$. In this context, it could be expected a decrease of AT2 expression in malignant tumors, that could lead to an imbalance favoring AT1 axis. However, the few data reported to date show divergent results, with both down and up-regulation of AT2 receptors in different tumors, and add controversy to the role of this receptor in cancer, which could be tumor-specific $(8,11,40)$.

In our study, AT2 showed similarities with AT1 staining pattern along the uninvolved mucosa-adenoma-CRC transition. Moreover, when data from CRC tissues were stratified by pathological variables, AT2 showed significant lower expression in CRCs with high local invasion (pT4), high stage (IV), high nodal (N2) and vascular invasion. These results agree with those reported previously in a short series of CRCs, which pointed this receptor as a CRC prognostic biomarker (27). Since studies in CRC cell lines have demonstrated apopototic and antiproliferative functions of AT2 signaling (41), it could be hypothesized that the loss of AT2 expression in advanced CRC cells could contribute to the evasion of these signals and to CRC progression. However, as pointed above for AT1, the biphasic expression of AT2 throughout the adenomatous polyp-CRC transition needs further investigations.

ACE2/Ang1-7/MAS axis has counter-regulatory effects on many physiological events induced by AT1 signaling (see Fig 1.) (7). However, its role in cancer depends on tumor type $(8,11,42,43)$. For example, MAS receptor activation inhibits angiogenesis and tumor progression of lung cancer cells (42) but increases metastatic potential of renal cancer cells (43).

Previous reports described high MAS receptor expression in CRC, both in primary tumors (25) and in liver metastases (23). Corroborating these results, we observed that MAS expression was significantly higher in CRCs than in the uninvolved mucosa and in adenomatous polyps. The increase of MAS expression from adenoma to CRC suggests a role for this receptor in the transition from benign to malignant behavior of this neoplastic process that needs to be elucidated.

In conclusion, the present study shows that the expression of AT1, AT2 and MAS receptors is significantly altered throughout the colorectal adenoma-carcinoma sequence and that loss of AT2 receptor is correlated with CRC progression. Taken into account that CRC is a major health problem in 
developed countries, a better understanding of the pathophysiological the role of RAS in colorectal carcinogenesis will be helpful for designing effective diagnostic, prognostic and therapeutic tools for this disease.

\section{Acknowledgments}

We wish to thank Arantza Pérez Dobaran (UPV/EHU) for her technical contribution to this study.

\section{Competing Interests}

The authors have declared that no competing interest exists.

\section{References}

1. Bray F, Ferlay J, Soerjomataram I, Siegel RL, Torre LA, Jemal A. Global cancer statistics 2018: GLOBOCAN estimates of incidence and mortality worldwide for 36 cancers in 185 countries. CA Cancer J Clin. 2018 Sep;68(6):394-424.

2. Galceran J, Ameijide A, Carulla M, Mateos A, Quirós JR, Rojas D, et al. Cancer incidence in Spain, 2015. Clin Transl Oncol Off Publ Fed Span Oncol Soc Natl Cancer Inst Mex. 2017 Jul;19(7):799-825.

3. Brenner $\mathrm{H}$, Chen $\mathrm{C}$. The colorectal cancer epidemic: challenges and opportunities for primary, secondary and tertiary prevention. Br J Cancer. 2018 Oct;119(7):785.

4. Fearon ER. Molecular genetics of colorectal cancer. Annu Rev Pathol. 2011;6:479-507.

5. Fearon ER, Vogelstein B. A genetic model for colorectal tumorigenesis. Cell. 1990 Jun 1;61(5):759-67.

6. Jass JR. Classification of colorectal cancer based on correlation of clinical, morphological and molecular features. Histopathology. 2007 Jan;50(1):113-30.

7. Fyhrquist F, Saijonmaa O. Renin-angiotensin system revisited. J Intern Med. 2008 Sep;264(3):224-36.

8. George AJ, Thomas WG, Hannan RD. The renin-angiotensin system and cancer: old dog, new tricks. Nat Rev Cancer. 2010 Nov;10(11):745-59.

9. Childers WK. Interactions of the renin-angiotensin system in colorectal cancer and metastasis. Int J Colorectal Dis. 2015 Jun;30(6):749-52.

10. Romero CA, Orias M, Weir MR. Novel RAAS agonists and antagonists: clinical applications and controversies. Nat Rev Endocrinol. 2015 Apr;11(4):242-52.

11. Wegman-Ostrosky T, Soto-Reyes E, Vidal-Millán S, Sánchez-Corona J. The renin-angiotensin system meets the hallmarks of cancer. J Renin-Angiotensin-Aldosterone Syst JRAAS. 2015 Jun;16(2):227-33.

12. Arrieta $\mathrm{O}$, Villarreal-Garza C, Vizcaíno G, Pineda B, Hernández-Pedro $\mathrm{N}$, Guevara-Salazar P, et al. Association between AT1 and AT2 angiotensin II receptor expression with cell proliferation and angiogenesis in operable breast cancer. Tumour Biol J Int Soc Oncodevelopmental Biol Med. 2015 Jul;36(7):5627-34

13. Perdomo-Pantoja A, Mejía-Pérez SI Reynoso-Noverón N, Gómez-Flores-Ramos L, Soto-Reyes E, Sánchez-Correa TE, et al. Angiotensinogen rs5050 germline genetic variant as potential biomarker of poor prognosis in astrocytoma. PloS One. 2018;13(11):e0206590.

14. Li XC, Zhang J, Zhuo JL. The vasoprotective axes of the renin-angiotensin system: Physiological relevance and therapeutic implications in cardiovascular, hypertensive and kidney diseases. Pharmacol Res. 2017 Nov;125(Pt A):21-38.

15. Song T, Choi CH, Kim MK, Kim M-L, Yun BS, Seong SJ. The effect of angiotensin system inhibitors (angiotensin-converting enzyme inhibitors or angiotensin receptor blockers) on cancer recurrence and survival: a meta-analysis. Eur J Cancer Prev Off J Eur Cancer Prev Organ ECP. 2017;26(1):78-85.

16. Lever AF, Hole DI, Gillis CR, McCallum IR, McInnes GT, MacKinnon PL, et al. Do inhibitors of angiotensin-I-converting enzyme protect against risk of cancer? Lancet Lond Engl. 1998 Jul 18;352(9123):179-84.

17. Makar GA, Holmes JH, Yang Y-X. Angiotensin-converting enzyme inhibitor therapy and colorectal cancer risk. J Natl Cancer Inst. 2014 Feb;106(2):djt374.

18. Osumi H, Matsusaka S, Wakatsuki T, Suenaga M, Shinozaki E, Mizunuma N. Angiotensin II type-1 receptor blockers enhance the effects of bevacizumab-based chemotherapy in metastatic colorectal cancer patients. Mol Clin Oncol. 2015 Nov;3(6):1295-300.

19. Wen Q, Dunne PD, O'Reilly PG, Li G, Bjourson AJ, McArt DG, et al. KRAS mutant colorectal cancer gene signatures identified angiotensin II receptor blockers as potential therapies. Oncotarget. 2016 Dec 10;8(2):3206-25.

20. Olschewski DN, Hofschröer V, Nielsen N, Seidler DG, Schwab A, Stock C. The Angiotensin II Type 1 Receptor Antagonist Losartan Affects NHE1-Dependent Melanoma Cell Behavior. Cell Physiol Biochem Int J Exp Cell Physiol Biochem Pharmacol. 2018;45(6):2560-76.

21. Xu J, Fan J, Wu F, Huang $Q$, Guo $M$, Lv $Z$, et al. The ACE2/Angiotensin-(1-7)/Mas Receptor Axis: Pleiotropic Roles in Cancer. Front Physiol. 2017; 8: 276

22. Koh SL, Ager EI, Costa PLN, Malcontenti-Wilson C, Muralidharan V, Christophi C. Blockade of the renin-angiotensin system inhibits growth of colorectal cancer liver metastases in the regenerating liver. Clin Exp Metastasis. 2014 Jan;31:395-405

23. Neo JH, Ager EI, Angus PW, Zhu J, Herath CB, Christophi C. Changes in the renin angiotensin system during the development of colorectal cancer liver metastases. BMC Cancer. 2010 Apr 10;10:134.

24. Nguyen L, Ager EI, Neo J, Christophi C. Regulation of colorectal cancer cell epithelial to mesenchymal transition by the renin angiotensin system. J Gastroenterol Hepatol. 2016 Oct;31(10):1773-82.

25. Bernardi S, Zennaro C, Palmisano S, Velkoska E, Sabato N, Toffoli B, et al. Characterization and significance of ACE2 and Mas receptor in human colon adenocarcinoma. J Renin-Angiotensin-Aldosterone Syst JRAAS. 2012 Mar;13(1):202-9.

26. Larrinaga G, Perez I, Ariz U, Sanz B, Beitia M, Errarte P, et al. Clinical impact of aspartyl aminopeptidase expression and activity in colorectal cancer. Transl Res J Lab Clin Med. 2013 Nov;162(5):297-308.

27. Zhou L, Luo Y, Sato S, Tanabe E, Kitayoshi M, Fujiwara R, et al. Role of two types of angiotensin II receptors in colorectal carcinoma progression. Pathobiol J Immunopathol Mol Cell Biol. 2014;81(4):169-75.

28. Amin MB, Greene FL, Edge SB, Compton CC, Gershenwald JE, Brookland RK, et al. The Eighth Edition AJCC Cancer Staging Manual: Continuing to build a bridge from a population-based to a more "personalized" approach to cancer staging. CA Cancer J Clin. 2017 Mar;67(2):93-9.

29. Biscay Epidemiological Surveillance Unit. Cáncer de colon y recto en Bizkaia. 2014. 2018

30. Hirasawa $K$, Sato $Y$, Hosoda $Y$, Yamamoto $T$, Hanai $H$ Immunohistochemical localization of angiotensin II receptor and local renin-angiotensin system in human colonic mucosa. J Histochem Cytochem Off J Histochem Soc. 2002 Feb;50(2):275-82.

31. Vaajanen A, Kalesnykas G, Vapaatalo H, Uusitalo H. The expression of Mas-receptor of the renin-angiotensin system in the human eye. Graefes Arch Clin Exp Ophthalmol Albrecht Von Graefes Arch Klin Exp Ophthalmol. 2015 Jul;253(7):1053-9.

32. Luo Y, Wang L, Wang J. Developing proteomics-based biomarkers for colorectal neoplasms for clinical practice: opportunities and challenges. Proteomics Clin Appl. 2013 Jan;7(1-2):30-41.

33. Paul M, Poyan Mehr A, Kreutz R. Physiology of local renin-angiotensin systems. Physiol Rev. 2006 Jul;86(3):747-803.

34. Sanz B, Perez I, Beitia M, Errarte P, Fernández A, Blanco L, et al. Aminopeptidase $\mathrm{N}$ activity predicts 5-year survival in colorectal cancer patients. J Investig Med Off Publ Am Fed Clin Res. 2015 Jun;63(5):740-6.

35. Miyajima A, Kosaka T, Kikuchi E, Oya M. Renin-angiotensin system blockade: Its contribution and controversy. Int J Urol Off J Jpn Urol Assoc. 2015 Aug:22(8):721-30.

36. Kedika R, Patel M, Pena Sahdala HN, Mahgoub A, Cipher D, Siddiqui AA. Long-term use of angiotensin converting enzyme inhibitors is associated with decreased incidence of advanced adenomatous colon polyps. J Clin Gastroenterol. 2011 Feb;45(2):e12-16.

37. Röcken C, Neumann K, Carl-McGrath S, Lage H, Ebert MPA, Dierkes I, et al. The Gene Polymorphism of the Angiotensin I-Converting Enzyme Correlates with Tumor Size and Patient Survival in Colorectal Cancer Patients. Neoplasia N Y N. 2007 Sep;9(9):716-22.

38. Berthon A, Drelon C, Ragazzon B, Boulkroun S, Tissier F, Amar L, et al. $\mathrm{WNT} / \beta$-catenin signalling is activated in aldosterone-producing adenomas and controls aldosterone production. Hum Mol Genet. 2014 Feb 15;23(4):889-905

39. Zhou L, Li Y, Hao S, Zhou D, Tan RJ, Nie J, et al. Multiple genes of the renin-angiotensin system are novel targets of $\mathrm{Wnt} / \beta$-catenin signaling. J Am Soc Nephrol JASN. 2015 Jan;26(1):107-20.

40. Dolley-Hitze T, Jouan F, Martin B, Mottier S, Edeline J, Moranne O, et al. Angiotensin-2 receptors (AT1-R and AT2-R), new prognostic factors for renal clear-cell carcinoma? Br J Cancer. 2010 Nov 23;103(11):1698-705.

41. Sun L, Wang W, Xiao W, Liang H, Yang Y, Yang H. Angiotensin II induces apoptosis in intestinal epithelial cells through the AT2 receptor, 
GATA-6 and the Bax pathway. Biochem Biophys Res Commun. 2012 Aug 10;424(4):663-8.

42. Soto-Pantoja DR, Menon J, Gallagher PE, Tallant EA. Angiotensin-(1-7) inhibits tumor angiogenesis in human lung cancer xenografts with a reduction in vascular endothelial growth factor. Mol Cancer Ther. 2009 Jun;8(6):1676-83.

43. Zheng S, Yang Y, Song R, Yang X, Liu H, Ma Q, et al. Ang-(1-7) promotes the migration and invasion of human renal cell carcinoma cells via Mas-mediated AKT signaling pathway. Biochem Biophys Res Commun. 2015 May 1;460(2):333-40. 